\title{
Predicting suicide attempts in young adults with histories of childhood abuse
}

\author{
Jelena Brezo, Joel Paris, Frank Vitaro, Martine Hébert, Richard E. Tremblay and Gustavo Turecki
}

\section{Background}

Although childhood abuse is an important correlate of suicidality, not all individuals who were abused as children attempt suicide.

\section{Aims}

To identify correlates and moderators of suicide attempts in adults reporting childhood physical abuse, contact sexual abuse, or both.

\section{Method}

A French-Canadian, school-based cohort $(n=1684)$ was prospectively followed.

\section{Results}

The identity of the abuser moderated the relationship of abuse frequency and suicide attempts, with individuals abused by their immediate family being at highest risk.
Although paternal education exhibited negative associations (OR $=0.71,95 \% \mathrm{Cl} 0.58-0.88)$, several externalising phenotypes had positive associations with suicide attempts: disruptive disorders (OR=3.10,95\% $\mathrm{Cl}$ 1.05-9.15), conduct problems (OR=1.09, 95\% Cl 1.01-1.19) and childhood aggression $(\mathrm{OR}=1.41,95 \% \mathrm{Cl} 1.08-1.83)$.

\section{Conclusions}

Characteristics of the abuser and abusive acts may be important additional indicators of risk for suicide attempts. Future research needs to employ developmental approaches to examine the extent and mechanisms by which childhood abuse contributes to the shared variance of suicidality, maladaptive traits and psychopathology.

\section{Declaration of interest}

None. Funding detailed in Acknowledgements.
Sexual abuse and, to a lesser extent, physical abuse in childhood have both been associated with suicidality. ${ }^{1}$ These associations involve multiple mediating and moderating influences, ${ }^{2}$ and confounding by other types of early adversity. Consequently, identifying factors that differentiate between those who become suicidal and those who do not among people abused as children is a major research and clinical challenge. To address this challenge, we first examined rates of non-fatal suicidal behaviours in adults reporting negative and positive histories of contact sexual abuse, physical abuse or both types of abuse. We then qualified contributions of early and proximal correlates of suicide attempts, examining psychiatric, socio-demographic, personality and experiential domains. ${ }^{3,4}$ A novel contribution of this study is the examination of gender and abuse characteristics - sexual abuse severity and frequency, and abuser identity - as moderators modifying the likelihood of individuals acting on their suicidal thoughts.

\section{Method}

\section{Study participants}

In 1986-1988, families of children attending nursery school in public francophone schools in Quebec, Canada, were recruited using a multistage sampling procedure. From 4488 participating children, two subsamples were selected for follow-up. The first was a randomly selected group of 1001 boys and 999 girls: the representative subsample (R). The second was an additional group of 593 boys and 424 girls, oversampled for children exhibiting disruptive behaviours: the disruptive subsample (D). To reduce cultural heterogeneity, only children whose parents were born in Canada and whose mother tongue was French were included; $88 \%$ were of non-Hispanic White ethnicity.

The assessment schedule had three stages:

(a) wave 1 (childhood), yearly assessments age 6-12 years; representative sample $n=2000$, disruptive sample $n=1017$; (b) wave 2 (mid-adolescence), average age 15.7 years (range 1518 ); representative sample $n=1233$, disruptive sample $n=482$;

(c) wave 3 (adulthood), average age 21.4 years (range 19-24); representative sample $n=1144$, disruptive sample $n=540$.

Participants who had died, refused participation or could not be contacted accounted for an overall attrition rate of $44 \%$ ( $R$ $43 \%$, D $47 \%$ ). To adjust for this, we conducted multivariate analyses with and without weights, representing individual probabilities of remaining in the study conditional on variables related to attrition: mean early socio-economic adversity, which was higher in non-responders $\left(\mathrm{R} 0.32\right.$ v. $0.25, t_{(1,1893.5)}=-7.410, P=0.0005$; D 0.39 v. $\left.0.32, t_{(1,1893.5)}=-2.161, P=0.031\right)$, and male gender, as males were overrepresented among non-responders (R 50\% v. $35 \%, \chi_{1}^{2}=46.05, P<0.05$; D $55 \%$ v. $\left.36 \%, \chi_{1}^{2}=36.30, P<0.05\right)$. The study was approved by the research ethics boards of the University of Montreal and McGill University. Written informed consent was obtained from all participants.

\section{Measures}

Wave 1

Family Socio-economic Adversity Index. The Family Socioeconomic Adversity Index (developed for this study) reflects the quality of the family environment. It is scored using a continuous scale based on the following measures: parental age at first child's birth, education, socio-economic status and living arrangements. Families at or below the 30th percentile in one of these areas (or non-intact families) were coded as having one adversity point. The total score is directly proportional to the level of early family adversity.

Social Behavior Questionnaire. The Social Behavior Questionnaire has 38 items measuring childhood behaviours and traits. ${ }^{5}$ We used teacher-assessed anxiousness (6 items) and aggression (13 items) at ages 6 years and 12 years. 
Wave 2

Diagnostic Interview Schedule for Children. Interviewers (psychology students) attended 1-1.5 days of training and a practice session in the use of the Diagnostic Interview Schedule for Children (DISC-2), ${ }^{6}$ using DSM-III-R criteria. ${ }^{7}$ Given the number of diagnoses and our interest in their collective impact, we considered disruptive disorders (attention-deficit hyperactivity, oppositional-defiant and conduct disorders), anxiety disorders (simple/social phobias, separation anxiety, panic, avoidant, overanxious and generalised anxiety disorders) and mood disorders (major depression and dysthymia) collectively.

Ideation. Pre-adolescent and adolescent suicidal ideation was assessed with one question: 'Have you already seriously thought about suicide?'

Suicide attempts. The presence and frequency of early-onset suicide attempts over lifetime and in the past 6 months were assessed using parental/adolescent responses to a DISC-2 question from the major depression module: 'Have you already attempted suicide?' Either parental or self-report was sufficient for a person to be classified as an attempter.

Wave 3

Income. Adult income in the previous year was recorded.

Diagnostic Interview Schedule for adults. Interviewers (psychology students) had 1-1.5 days training and a practice session in the use of the Diagnostic Interview Schedule (DIS) for adults, based on DSM-III-R criteria. ${ }^{7}$ To reduce the number of statistical tests and evaluate their group impact, mood disorders (major depressive episode, mania and dysthymia) and anxiety disorders (generalised anxiety, panic and phobias) were considered collectively. Given the evidence of their independent contributions to suicidality, misuse and/or dependence on drugs, alcohol and nicotine were considered individually.

Scale for Suicide Ideation. The Scale for Suicide Ideation ${ }^{8}$ is a 19-item scale measuring current attitudes towards living/dying, characteristics of suicidal ideation, and actualisation of contemplated attempt. Cronbach's $\alpha$ was 0.63 .

Suicidal Intent Scale. The Suicidal Intent Scale is a 20-question instrument designed for administration to people who have attempted suicide. ${ }^{9}$ It assesses the 'intensity' of the wish to die at the most recent attempt $(\alpha=0.64)$.

Suicide attempts. Suicide attempt history in adults was assessed with Suicidal Intent Scale questions ('Have you already attempted suicide?' 'How many attempts have you made prior to the one in question?'). Late-onset suicide attempts were those made after the age of 18 years. Repeated attempts occurred more than once according to parental or self-report. Lifetime suicide attempt status was based on both adolescent and adult assessments. Suicide attempts were defined as acts of self-injury with at least some level of suicidal intent.

Ideation. Suicidal ideation (lifetime) was a three-level composite index based on current suicidal thoughts (Scale for Suicide Ideation); lifetime suicidal thoughts in adulthood (DIS: 'Have you ever thought of suicide?') and pre/adolescent suicidal ideation. Individuals were classified into non-ideator (score 0 ), transient ideator (score 1) and persistent ideator (score 2-3) groups.
Personality pathology. The Diagnostic Assessment of Personality Pathology instrument assesses 18 personality traits, 7 of which are related to constructs studied in relation to suicidal behaviours. ${ }^{10}$ These include affective instability, anxiousness, conduct problems, cognitive-perceptive dysregulation, identity problems, insecure attachment and stimulus-seeking ( $\alpha$ values $0.85-0.93$ ).

Barratt Impulsiveness Scale. The Barratt Impulsiveness Scale is a 30-item instrument assessing trait impulsivity by enquiring about general ways of acting/thinking across situations $(\alpha=0.81){ }^{11}$

Childhood physical abuse. We selected a subset of 14 questions evaluating the presence and frequency of severe/very severe physical aggression, abuse and injuries perpetrated by each parent against the respondent as a child. ${ }^{12}$

Childhood sexual abuse. The Childhood Sexual Abuse Scale measures incidents of sexual violence to age 18 years. ${ }^{13}$ We selected items evaluating abusive acts involving physical contact - fondling or sexual (vaginal, anal, oral) - perpetrated by family members, school peers or staff, short-term or long-term romantic acquaintances, or strangers.

Stressful life events. Stressful life events in the past year included atypical/severe stressful events related to finances, school/work, death of a close person, illness/serious injury to self/others, parental separation/divorce, and partner/children difficulties.

Social support. The Social Support Scale measures perceived support by friends and family using 15 statements assessed with Likert scales $(\alpha=0.88) .{ }^{14}$

\section{Data analyses}

Univariate analyses

We first used $\chi^{2}$ analysis of variance (ANOVA), correcting for the number of tests $(P=0.0015,34$ tests), to preselect variables for inclusion in multivariate analyses. We investigated four domains implicated in the risk of suicide attempts: socio-demographic (early socio-economic adversity, adult income and gender); psychiatric (adolescent/adult mood/anxiety diagnoses, adolescent disruptive disorder and adult nicotine, alcohol and drug dependence/misuse, adolescent/adult comorbidity and lifetime suicidal ideation); experiential (social support and stressful events); and personality traits (childhood disruptiveness, childhood/adult anxiousness; adult impulsivity, affective instability, conduct problems, cognitive-perceptive dysregulation, identity problems, insecure attachment, stimulus-seeking traits and adolescent self-esteem).

\section{Multivariate analyses}

Participants who had experienced childhood abuse were classified into three non-overlapping groups according to the type of abuse - contact sexual abuse, physical abuse, or both - and compared with their non-abused peers. Binary logistic regression was used to identify both the correlates of lifetime suicide attempt histories and odds of suicide attempts and suicidal ideas in the three abuse groups relative to the non-abuse control group. These analyses were adjusted for disruptive subsample membership (as disruptiveness is related to the impulsive-aggressive dimension linked to suicidality) and for gender, given the well-known gender differences in abuse and suicidality rates. ${ }^{3}$

We used the Nagelkerke $R^{2}$ to estimate the proportion of the total variance explained in our dependent variable (history of 
suicide attempts). We also used the Hosmer-Lemeshow test, a $\chi^{2}$-based goodness-of-fit test, to investigate the null hypothesis predicting that the identified model fits the data well. A $P$-value greater than 0.05 indicates that model predictions are not significantly different from the observed values, failing to reject the null hypothesis.

We first performed main effect analyses investigating univariately significant variables first within and then across the four risk domains using a threshold of $P>0.05$. We then tested first-order moderators affecting the relationship of lifetime suicide attempts and suicidal ideation: gender (physical-abuse group); abuser identity, abuse frequency and abuse severity (sexual-abuse group). Analyses were performed with and without weights. Cook's test identified one outlier (Cook's indicator=2.41) in the sexual-abuse group, which was excluded from our final analyses. We also addressed multicollinearity by centring continuous variables. Finally, we examined the latter for normality (a probability-probability plot revealed a modest departure from normality for the trait of conduct problems) and for linearity (ANOVA tests of linearity suggested non-significance of non-linear components at $P<0.05$ ).

\section{Results}

Contact sexual abuse in childhood was reported by $9.9 \%$ (men $2.7 \%$, women $18.0 \% ; \chi_{1}^{2}=146.40, P=0.0005$ ), physical abuse by $20.6 \%$ (men $26.3 \%$, women $14.3 \% ; \chi_{1}^{2}=9.46, P=0.002$ ) and both by $8.2 \%$ (men $4 \%$, women $12.8 \%$; $\chi_{1}^{2}=43.36, P=0.0005$ ) of our participants. The least severe type of contact sexual abuse, involving touch, was, at $49 \%$, the most frequent. Threats and force were reported in $22 \%$ and $30 \%$ of the remaining sexual abuse cases respectively. In a third of the sexual abuse cases the abuser was a family member, and in about two-thirds the abuse occurred on multiple occasions.

Our prediction that the percentage of individuals reporting a history of non-fatal suicidal behaviours would be higher among those who had been abused, especially those reporting both abuse types, ${ }^{15}$ was largely met (Table 1 ). Overall, histories of suicide attempts $\left(\chi_{3}^{2}=102.07, P=0.0005\right)$ and ideation $\left(\chi_{3}^{2}=69.17\right.$, $P=0.0005)$ were more frequently reported in the abused group than in the non-abused group. Moreover, we observed a dosedependent relationship in the total sample: the non-abused group had a lower prevalence of lifetime suicide attempts (6.0\%) than the physical abuse (11.7\%), sexual abuse (14.8\%) and both abuse types (32.2\%) groups. At $25.4 \%$, the prevalence of lifetime suicidal ideation in the non-abused group was also lower than in the physical abuse $(36.6 \%)$, sexual-abuse $(49.6 \%)$ and both abuse types $(58.1 \%)$ groups. In models adjusted for gender and disruptive group membership, those reporting both types of abuse had a 5-14 times greater risk for the four subtypes of suicide attempts and 3-6 times greater odds of suicidal ideas. The sexual-abuse group had higher odds of repeated and late-onset suicide attempts and both types of suicidal thoughts compared with the physicalabuse group. Inspection of gender-stratified odds ratios suggests that the gradient in most suicidal behaviours is confined to the female subsample.

\section{Identification of correlates and moderators of suicide attempts}

Our hypotheses regarding the correlates of suicide attempts focused on four domains. Because high social support buffers

Table 1 Relationship between history of childhood abuse, and suicidal ideation or attempts

\begin{tabular}{|c|c|c|c|c|c|c|c|}
\hline \multirow[b]{2}{*}{ Suicidal attempt or ideation } & \multirow{2}{*}{$\begin{array}{l}\begin{array}{l}\text { No childhood abuse } \\
\text { (males } n=575 \\
\text { females } n=425) \\
\%\end{array}\end{array}$} & \multicolumn{2}{|c|}{$\begin{array}{l}\text { Childhood physical abuse } \\
\text { (males } n=225 \\
\text { females } n=111 \text { ) }\end{array}$} & \multicolumn{2}{|c|}{$\begin{array}{l}\text { Childhood sexual abuse } \\
\text { (males } n=23 \text {, } \\
\text { females } n=139 \text { ) }\end{array}$} & \multicolumn{2}{|c|}{$\begin{array}{l}\text { Physical and sexual abuse } \\
\text { (males } n=34 \\
\text { females } n=99 \text { ) }\end{array}$} \\
\hline & & $\%$ & OR $(95 \% \mathrm{Cl})^{\mathrm{a}}$ & $\%$ & OR $(95 \% \mathrm{Cl})^{\mathrm{a}}$ & $\%$ & OR $(95 \% \mathrm{Cl})^{\mathrm{a}}$ \\
\hline \multicolumn{8}{|l|}{ Single attempt } \\
\hline Men & 4.7 & 10.1 & $2.3(1.1-4.8)^{\star}$ & 25.0 & $6.8(2.0-23.3)^{\star *}$ & 8.3 & $1.8(0.4-8.5)$ \\
\hline Women & 7.6 & 12.9 & $1.8(0.9-3.6)$ & 11.3 & $1.5(0.8-3.0)$ & 31.4 & $5.4(2.9-10.2)^{\star * *}$ \\
\hline Total & 6.2 & 11.2 & $2.0(1.2-3.2)^{\star *}$ & 13.0 & $1.9(1.1-3.5)^{\star}$ & 25.5 & $4.7(2.7-8.1)^{\star \star \star}$ \\
\hline \multicolumn{8}{|l|}{ Repeated attempts } \\
\hline Men & 1.1 & 3.8 & $2.9(0.7-11.1)$ & 0.0 & $3.7(1.5-9.3)^{\star *}$ & 8.3 & $6.3(1.1-37.4)^{*}$ \\
\hline Women & 2.5 & 4.7 & $1.9(0.6-6.2)$ & 8.9 & $3.3(1.4-7.9)^{* *}$ & 29.4 & $16.0(6.9-37.3)^{* * *}$ \\
\hline Total & 1.8 & 4.2 & $2.4(1.0-5.9)^{*}$ & 8.1 & & 23.9 & $13.8(6.6-29.0)^{* * *}$ \\
\hline \multicolumn{8}{|l|}{ Early-onset attempt ${ }^{\mathrm{b}}$} \\
\hline Men & 2.4 & 7.0 & $2.8(1.1-7.1)^{\star}$ & 0.0 & $1.7(0.8-3.5)$ & 4.3 & $1.5(18-12.6)$ \\
\hline Women & 5.7 & 7.4 & $1.3(0.5-3.2)$ & 8.9 & $1.6(0.8-3.3)$ & 20.2 & $5.4(2.7-10.9)^{* * *}$ \\
\hline Total & 4.1 & 7.2 & $1.9(1.0-3.6)^{\star}$ & 8.0 & & 16.8 & $4.7(2.5-8.9)^{\star * *}$ \\
\hline \multicolumn{8}{|l|}{ Late-onset attempt ${ }^{\mathrm{C}}$} \\
\hline Men & 3.8 & 6.9 & $2.0(0.9-4.6)$ & 25.0 & $8.2(2.3-28.8)^{\star \star}$ & 11.5 & $3.4(0.9-12.7)$ \\
\hline Women & 4.1 & 9.3 & $2.4(1.0-5.7)^{\star}$ & 9.6 & $2.6(1.2-5.6)^{*}$ & 28.6 & $11.8(5.9-23.5)$ \\
\hline Total & 3.9 & 7.9 & $2.2(1.2-4.0)^{*}$ & 11.3 & $2.9(1.5-5.7)^{\star *}$ & 24.8 & $9.0(5.0-16.0)^{* * *}$ \\
\hline \multicolumn{8}{|l|}{ Transient ideation $^{d}$} \\
\hline Men & 15.2 & 22.7 & $1.8(1.1-2.9)^{*}$ & 28.6 & $2.3(0.7-7.6)$ & 18.2 & $1.4(0.4-4.3)$ \\
\hline Women & 18.8 & 24.5 & $1.5(0.9-2.7)$ & 28.3 & $2.2(1.4-3.6)^{* *}$ & 30.1 & $3.3(1.8-5.9)^{* * *}$ \\
\hline Total & 17.0 & 23.4 & $1.7(1.2-2.4)^{\star *}$ & 28.4 & $2.2(1.4-3.4)^{\star *}$ & 27.6 & $2.7(1.6-4.5)^{* * *}$ \\
\hline \multicolumn{8}{|l|}{ Persistent ideatione } \\
\hline Men & 7.7 & 12.1 & $1.8(0.9-3.4)$ & 7.1 & $1.1(0.1-9.3)$ & 13.6 & $1.9(0.5-6.9)$ \\
\hline Women & 9.0 & 14.9 & $2.0(1.0-3.9)^{\star}$ & 22.8 & $3.8(2.1-6.6)^{\star * *}$ & 34.9 & $8.1(4.3-15.1)$ \\
\hline Total & 8.4 & 13.2 & $1.9(1.2-3.1)^{\star}$ & 21.3 & $3.2(1.9-5.3)^{\star \star \star}$ & 30.5 & $5.9(3.4-10.0)^{* * *}$ \\
\hline \multicolumn{8}{|c|}{$\begin{array}{l}\text { a. Odds ratios with } 95 \% \text { confidence intervals for a given suicidal phenotype in an abused group relative to non-abused controls in models adjusted for disruptive group membership } \\
\text { and gender. } \\
\text { b. Suicide attempt made before age } 18 \text { years. } \\
\text { c. Suicide attempt made after age } 18 \text { years. } \\
\text { d. Reported suicidal ideation during follow-up once. } \\
\text { e. Reported suicidal ideation during follow-up at least twice. } \\
{ }^{*} P<0.05, * \star P<0.01, * \star * P<0.001 \text {. }\end{array}$} \\
\hline
\end{tabular}


the impact of stress and guards against social isolation (two important triggers of suicidal behaviours), we expected social support and stressful life events ${ }^{16}$ to represent significant correlates of suicide attempts. These expectations were not met in any of our abuse groups. Second, among socio-demographic factors, as expected, ${ }^{3}$ female gender was associated with suicide attempts in the group who experienced both types of abuse, as was one of the four aspects of early socio-economic adversity (paternal education: physical-abuse group $\mathrm{OR}=0.71,95 \% \mathrm{CI}$ 0.58-0.88). In contrast to previous research, neither adult income nor the remaining three components of early socio-economic adversity were related to suicide attempts. ${ }^{17,18}$

Our hypothesis that suicidal ideation ${ }^{19}$ might be of relevance for suicide attempts was met in all three abuse groups (sexual abuse $\mathrm{OR}=6.7,95 \%$ CI 2.6-17.2; physical abuse OR=5.8, 95\% CI 2.9-11.7; both OR=4.5, 95\% CI 2.1-9.6). In terms of psychiatric diagnoses, in contrast to previous research evidence, ${ }^{19}$ we were unable to confirm the involvement of adolescent mood and anxiety disorders or adult substance misuse. ${ }^{20}$ The opposite was true for disruptive disorder, an important correlate of suicide attempts in our physical-abuse group ( $\mathrm{OR}=3.1,95 \%$ CI $1.1-9.1)$ (Table 2).

Fourth, we predicted significant contributions of several personality traits related to emotional dysregulation and impulsiveaggression, ${ }^{4}$ given their involvement in essential aspects of functioning: self-perception (identity problems and self-esteem), ${ }^{21}$ interpretation (cognitive-perceptive dysregulation), interaction (submissiveness, disruptiveness, insecure attachment, social avoidance and suspiciousness) and reaction to social environments (passive-aggressivity, affective instability, anxiousness). Two of these traits - childhood aggression/disruptiveness (sexualabuse group $\mathrm{OR}=1.4,95 \%$ CI $1.1-1.8$; both abuse types $\mathrm{OR}=4.6$, 95\% CI 1.1-18.2) and adolescent/adult conduct problems (both abuse types OR=1.1, 95\% CI 1.01-1.2) - made significant contributions (Tables 3 and 4).

Evidence for gender-based moderation of the risk of suicide attempts and suicidal ideation, especially in people experiencing childhood physical abuse, has been offered before. ${ }^{15,22}$ In our study, however, gender did not act as a moderator of the relationship of suicidal ideation and suicide attempts in the physicalabuse group.

On the basis of previous research suggesting that severe childhood sexual abuse - that involving fathers or stepfathers, or repeated abuse - may be strongly associated with suicide attempts, ${ }^{23}$ we also tested evidence of moderation by three sexual abuse characteristics: abuser identity, abuse frequency and abuse severity. Although none of the hypothetical moderating effects was significant, we did observe an interaction between abuse frequency and abuser identity $(\mathrm{OR}=3.4,95 \%$ CI 1.4-8.1). Abuse frequency had a conditional effect on suicide attempts, and was, in turn, moderated by abuser identity. Repeated sexual abuse had a stronger association with suicide attempts than did onetime abuse (Fig. 1). Relative risk increased with the degree of relatedness between the child and the abuser: compared with participants reporting no history of childhood abuse, those abused by a non-related person $(\mathrm{RR}=2.3)$, a member of their extended family $(\mathrm{RR}=3.4)$ or a member of their immediate family $(R R=5.0)$ had progressively higher likelihoods of reporting suicide attempts.

\section{Discussion}

To our knowledge, this is the first community-based study examining abuse characteristics as moderators of suicide attempt risk in adults with a history of childhood physical abuse, contact sexual abuse, or both. This stratification helped us to overcome the classification problems frequently encountered in maltreatment studies, ${ }^{24}$ and enabled us to identify protective, risk and moderating influences that may explain differences in suicide attempt risk across abuse sub-populations.

Table 2 Correlates of suicide attempts in participants reporting childhood physical abuse

\begin{tabular}{|c|c|c|}
\hline & $B$ (s.e.) & $\operatorname{Exp}[B](95 \% \mathrm{Cl})$ \\
\hline \multicolumn{3}{|l|}{ Confounders } \\
\hline Disruptive sample membership ${ }^{a}$ & $-0.54(0.64)$ & $0.58(0.17-2.04)$ \\
\hline Gender & $0.34(0.47)^{b}$ & $3.69(0.95-14.39)$ \\
\hline \multicolumn{3}{|l|}{ Regressors } \\
\hline Paternal education & $-0.34(0.11)^{\star \star *}$ & $0.71(0.58-0.88)$ \\
\hline Disruptive disorders & $1.13(0.55)^{*}$ & $3.10(1.05-9.15)$ \\
\hline Lifetime suicidal ideas & $1.76(0.35)^{\star \star *}$ & $5.84(2.91-11.67)$ \\
\hline Model indices & \multicolumn{2}{|c|}{$\begin{array}{l}\text { Model fit: } \chi_{5}^{2}=50.99, P=0.0005 \\
\text { Nagelkerke } R^{2}=47.9 \% \\
\text { Hosmer-Lemeshow test: } \chi^{2}{ }_{8}=6.50 \\
P=0.59\end{array}$} \\
\hline \multicolumn{3}{|c|}{$\begin{array}{l}\text { a. Assessed at } 6 \text { years of age. } \\
\text { b. Statistical trend }(0.05<P<0.10 \text { ); all analyses were weighted and all continuous } \\
\text { variables centred. }\end{array}$} \\
\hline
\end{tabular}

Table 3 Correlates of suicide attempts in participants reporting childhood sexual abuse ${ }^{a}$

B (s.e.) $\operatorname{Exp}[B](95 \% \mathrm{Cl})$

Confounders

Disruptive sample membership ${ }^{\mathrm{b}} \quad 1.01(0.83) \quad 2.73(0.53-14.06)$ Gender $-1.44(1.11) \quad 0.24(0.03-2.09)$

Regressors

Lifetime suicidal ideas

Abuse frequency

and abuser identity $\quad 1.21(0.45)^{* *} \quad 3.37(1.40-8.13)$ Aggression $^{\text {C }}$ $0.34(0.13)^{*} \quad 1.41(1.08-1.83)$

Model indices Model fit: $\chi^{2}{ }_{5}=44.85, P=0.0005$ Nagelkerke $R^{2}=57.9 \%$ Hosmer-Lemeshow test: $\chi_{8}^{2}=2.32, P=0.97$

All analyses were weighted and all continuous variables centred.

b. Assessed at age 6 years

b. Assessed at age 6 years.

${ }^{*} P<0.05, * * P<0.01,{ }^{* \star \star} P<0.001$

Table 4 Correlates of suicide attempts in participants

reporting both sexual and physical abuse in childhood ${ }^{a}$

$B$ (s.e.) $\operatorname{Exp}[B](95 \% \mathrm{Cl})$

Confounders

Disruptive sample membership $^{\mathrm{b}} 1.52(0.70)^{*} \quad 4.59(1.15-18.23)$ Gender $5.56(1.76)^{* *} \quad 259.2(8.30-8093.01)$

Regressors

Lifetime suicidal ideas

Conduct problems

$1.49(0.39)^{* * *} \quad 4.45(2.07-9.58)$ $0.09(0.04)^{*} \quad 1.09(1.01-1.19)$

Model indices Model fit: $\chi^{2}{ }_{4}=54.24, P=0.0005$ Nagelkerke $R^{2}=62.0 \%$ Hosmer-Lemeshow test: $\chi_{8}^{2}=4.83$, $P=0.78$

a. All analyses were weighted and all continuous variables centred b. Assessed at age 6 years.

$P<0.05,{ }^{*} P<0.01,{ }^{* * *} P<0.001$ 


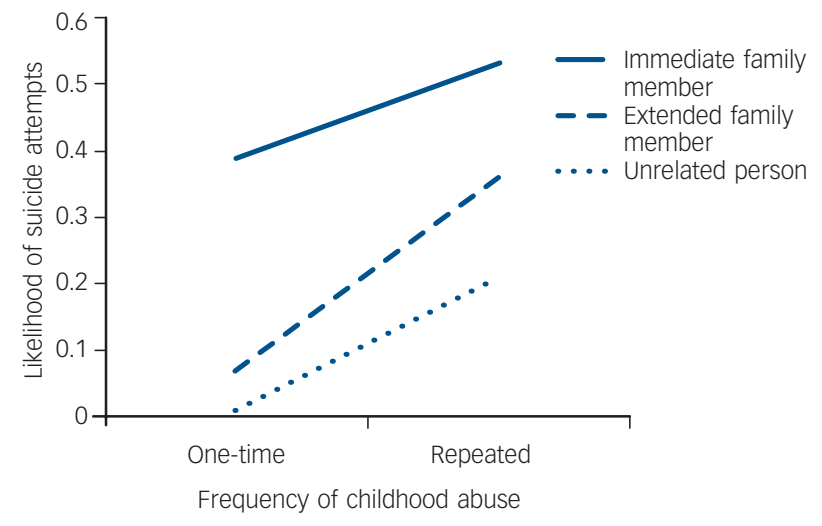

Fig. 1 Interaction of abuse frequency and abuser identity.

\section{Distribution of suicidal behaviours}

For the most part, participants with no history of childhood abuse had the lowest odds of non-fatal suicidal behaviours, and those reporting physical abuse, sexual abuse or both abuse types respectively had progressively higher odds of such behaviours. The existence of such a gradient has been suggested previously. ${ }^{25}$ Stratification by gender further revealed that the gradient may be specific to female suicide attempters and ideators, corroborating evidence for gender-specific psychiatric consequences across abuse types. $^{26}$ This heterogeneity might be related to gender-specific gene-environment interactions, neurobiological changes, coping responses to childhood abuse and differential exposure levels to childhood trauma. ${ }^{27}$

\section{Correlates and moderators of suicide attempts}

Our primary hypothesis regarding Axis I disorders was supported only in adults reporting physical abuse in childhood. Satisfying criteria for attention-deficit hyperactivity disorder, conduct disorder and/or oppositional-defiant disorder tripled the likelihood of a positive suicide attempt history. Disruptive disorder symptoms, especially in those reporting physical abuse, have already been linked to suicidal behaviours. ${ }^{28}$ We were, however, unable to test if this association was mediated by substance use disorders, as previously suggested. ${ }^{28}$ This possibility seems unlikely in our sample, as substance misuse was not related to suicide attempts. Anxiety and mood disorders were similarly not significant, either because their contribution was limited to shared variance with suicidal ideation or because they are not important intermediaries between childhood abuse and suicide attempts.

Interestingly, we found that externalising personality traits assessed at different life stages may be of relevance to suicide attempts. Conduct problems - self-reported tendencies to engage in acts of vandalism or theft, alcohol intoxication, and bullying or threats of violence - contributed to the variance in suicide attempts in our group with both types of abuse. Furthermore, disruptive-aggressive personality traits in childhood were significant in both the combined-abuse group and the sexual-abuse group. These traits are related to impulsivity-aggression, a putative mediator of suicide risk. ${ }^{29}$ Similar traits have been implicated across age and gender groups. ${ }^{18}$

Explanations for the involvement of externalising tendencies impulsive-aggressive personality traits and disruptive disorders are likely to involve interplays of abusive environments and genes. For example, externalising behaviour is predicted by high-intensity family conflict, a situation more likely to arise in abusive households. ${ }^{30}$ Childhood abuse itself may influence the development of impulsivity and aggression, ${ }^{31}$ although its precise role is unknown. Our data demonstrated that aggression at age 6 years (our earliest personality measure) was most relevant, among those who had attempted suicide, in participants who reported the most severe childhood abuse type (both physical and sexual). Additionally, relative to sexually abused children, those experiencing both physical and sexual abuse were more likely to report abuse by family members rather than by unrelated persons, further supporting the notion of compound family adversity in abusive households. Ultimately, abuse in children may be not only involved in the aetiology of externalising tendencies but also a negative reinforcer of such tendencies through reactive geneenvironment correlations: in other words, externalising behaviours may provoke negative reactions by adults and peers, leading to social difficulties, an important motivator of suicide attempts.

Unlike externalising tendencies, which exhibited some abuse specificity, suicidal thoughts made consistent contribution across abuse types in our study. Persistent suicidal ideation made suicide attempts 5-6 times more likely in those with a history of childhood abuse. Its relationship with suicide attempts was additive rather than moderated by gender and abuse characteristics, in contrast to our hypotheses. Suicidal thoughts, however, may be mediators between suicide attempts and maladaptive coping responses related to abuse.

Our exploration of the effect of childhood sexual abuse characteristics indicated that the impact of abuse frequency on suicide attempts depended on the identity of the abuser. Repeated abuse was, generally, more strongly associated with suicide attempts than was one-time abuse. Furthermore, sexual abuse by a member of the immediate family - father, stepfather or brother, for example - carried the greatest risk, whereas abuse perpetrated by an extended family member (uncle, cousin) or an unrelated individual (an acquaintance, romantic partner or stranger) carried intermediate and weaker risks respectively. There are at least two plausible explanations for this pattern. First, abuse by a father or stepfather is considered especially traumatic, ${ }^{22}$ possibly because such abuse is more likely to occur in families with multiple problems and also because these families cannot provide safe and healing conditions following abuse. Second, abuse by close family members, who are expected to be among our main, lifelong sources of support, may have long-term consequences on the development of healthy attachment patterns necessary for mental health. ${ }^{32}$

Although we examined possible protective influences of adolescent self-esteem, social support, and childhood and adult environments, only paternal education was found to have such effect. Low parental education has already been recognised as a risk factor for childhood abuse. ${ }^{16}$ We found it also to be strongly correlated with socio-economic status $(r=0.58, P=0.0005)$, another factor positively related to mental health and exposure to abuse. ${ }^{25}$ Better-educated parents might provide a more stable and healthy environment, one that would lower the likelihood of abuse taking place or reduce its impact. They might, furthermore, be less likely to use corporal punishment and similar disciplinary methods. When facing challenging situations themselves, educated parents might also model more adequate coping behaviours rather than resort to suicidal gestures and/or externalising behaviours.

In summary, the three abuse groups have both shared and distinct correlates of suicide attempts across diverse risk domains. Additional longitudinal studies need to examine childhood abuse in relation to the onset and developmental course of psychosocial problems, addressing moderating and mediating influences 
involving characteristics of abusive acts, the person abused, and the abuser.

Alternative methodological explanations of observed findings must also be noted. Our study population included self-reported abuse victims, excluding individuals who repressed memories of such events or chose not to report them. Nevertheless, we found those self-reporting abuse to be at higher risk of attempting suicide than those reporting no childhood abuse. Furthermore, not having information on the proportion of those who had received psychosocial interventions following abuse disclosure, we were unable to control for the possible confounding effects of such interventions. The lack of external validation of abusive experiences and attachment security, possibility of measurement error, and the small number of sexually abused male participants who had attempted suicide also merit consideration. We also note a modest departure from normality of the trait of conduct problems, although logistic regression is believed to be relatively robust to such departures.

To address the suboptimal psychometric properties of the suicidal ideation and intent scales - possibly attributable to translation problems - we used multiple instruments to assess suicidality. Still, more information is needed on the means used at self-injury. These limitations notwithstanding, our findings confirm the association between suicide attempts and childhood abuse, and involvement of both additive and interactive influences.

\footnotetext{
Jelena Brezo, PhD, McGill Group for Suicide Studies, Douglas Hospital Research Center; Joel Paris MD, Department of Psychiatry, MCGill University; Frank Vitaro, PhD, GRIP, University of Montreal; Martine Hébert, PhD, Department of Sexology, PhD, GRIP, University of Montreal; Martine Hébert, PhD, Department of Sexolo
University of Quebec; Richard E. Tremblay, PhD, GRIP, University of Montreal; Gustavo Turecki, MD, PhD, McGill Group for suicide Studies, Douglas Hospital Research Center, and Department of Psychiatry, McGill University, Montreal, Quebec, Canada

Correspondence: Dr Gustavo Turecki, McGill Group for Suicide Studies, 6875 Boulevard LaSalle, Montreal, Quebec H4H 1R3, Canada. Email: gustavo.turecki@mcgill.ca

First received 15 Mar 2007, final revision 6 Feb 2008, accepted 20 Mar 2008
}

\section{Acknowledgements}

We thank Dr Alexandre Bureau for his valuable comments on the manuscript. The study was supported in part by the Canadian Institutes of Health Research (grant MOP 151060).

\section{References}

1 Santa Mina EE, Gallop RM. Childhood sexual and physical abuse and adult self-harm and suicidal behaviour: a literature review. Can J Psychiatry 1998; 43: 793-800.

2 Kaslow NJ, Thompson MP, Meadows LA, Jacobs D, Chance S, Gibb B, Bornstein $\mathrm{H}$, Hollins L, Rashid A, Phillips $\mathrm{K}$. Factors that mediate and moderate the link between partner abuse and suicidal behavior in African American women. J Consult Clin Psychol 1998; 66: 533-40.

3 Beautrais AL. Risk factors for suicide and attempted suicide among young people. Aust N Z J Psychiatry 2000; 34: 420-36.

4 Brezo J, Paris J, Turecki G. Personality traits as correlates of suicidal ideation suicide attempts, and suicide completions: a systematic review. Acta Psychiatr Scand 2006; 113: 180-206.

5 Masse LC, Tremblay RE. Behavior of boys in kindergarten and the onset of substance use during adolescence. Arch Gen Psychiatry 1997; 54: 62-8.

6 Breton JJ, Bergeron L, Valla JP, Berthiaume C, St-Georges M. Diagnostic interview schedule for children (DISC-2.25) in Quebec: reliability findings in light of the MECA study. J Am Acad Child Adolesc Psychiatry 1998; 37 1167-74.
7 Robins LN, Cottler L, Bucholtz K, Compton W. Diagnostic Interview Schedule for DSM-IV. Washington University, 1995.

8 Beck AT, Kovacs M, Weissman A. Assessment of suicidal intention: the Scale for Suicide Ideation. J Consult Clin Psychol 1979; 47: 343-52.

9 Beck RW, Morris JB, Beck AT. Cross-validation of the Suicidal Intent Scale. Psychol Rep 1974; 34: 445-6.

10 Livesley WJ, Jang KL, Vernon PA. Phenotypic and genetic structure of traits delineating personality disorder. Arch Gen Psychiatry 1998; 55: 941-8.

11 Barratt E. Impulsive subtraits: arousal and information processing. In Motivation, Emotion, and Personality (eds JT Spence, CE Izard): 137-146. Elsevier, 1985

12 Straus MA, Hamby SL, Boney-McCoy S, Sugarman DB. The revised conflict tactics scales (CTS2). Development and preliminary psychometric data. J Fam Issues 1996; 17: 283-316.

13 Felitti VJ, Anda RF, Nordenberg D, Williamson DF, Spitz AM, Edwards V, Koss MP, Marks JS. Relationship of childhood abuse and household dysfunction to many of the leading causes of death in adults. The Adverse Childhood Experiences (ACE) study. Am J Prev Med 1998; 14: 245-8.

14 Turner RJ. Social support: conceptualization, measurement, and implications for mental health. Res Community Ment Health 1983; 3: 67-111.

15 Windle M, Windle RC, Scheidt DM, Miller GB. Physical and sexual abuse and associated mental disorders among alcoholic inpatients. Am J Psychiatry 1995; 151: 1322-8.

16 Straus MA. Social stress and marital violence in a national sample of American families. Ann N Y Acad Sci 1980; 347: 229-50.

17 Beautrais AL, Wells JE, McGee MA, Oakley Browne MA. Suicidal behaviour in Te Rau Hinengaro: the New Zealand Mental Health Survey. Aust $N \mathrm{ZJ}$ Psychiatry. 2006; 40: 896-904.

18 King RA, Schwab-Stone M, Flisher AJ, Greenwald S, Kramer RA, Goodman SH, Lahey BB, Shaffer D, Gould MS. Psychosocial and risk behavior correlates of youth suicide attempts and suicidal ideation. J Am Acad Child Adolesc Psychiatry 2001; 40: 837-46.

19 O'Boyle M, Brandon EA. Suicide attempts, substance abuse, and personality. J Subst Abuse Treat 1998; 15: 353-6.

20 Kessler RC, Borges G, Walters EE. Prevalence of and risk factors for lifetime suicide attempts in the National Comorbidity Survey. Arch Gen Psychiatry 1999; 56: 617-26.

21 Dinwiddie SH, Heath AC, Dunne MP, Bucholz KK, Madden PA, Slutske WS, Bierut $\sqcup$, Statham DB, Martin NG. Early sexual abuse and lifetime psychopathology: a co-twin-control study. Psychol Med 2000; 30: 41-52.

22 D'Eramo KS, Prinstein MJ, Freeman J, Grapentine WL, Spirito A. Psychiatric diagnoses and comorbidity in relation to suicidal behavior among psychiatrically hospitalized adolescents. Child Psychiatry Hum Dev 2004; 35 21-35.

23 Hébert M, Parent N, Daignault IV, Tourigny M. A typological analysis of behavioral profiles of sexually abused children. Child Maltreat 2006; 11 : 203-16.

24 Kinard EM. Methodological issues and practical problems in conducting research on maltreated children. Child Abuse Negl 1994; 18: 645-56.

25 Beitchman JH, Inglis A, Schachter D. Child psychiatry and early intervention: II. The internalizing disorders. Can J Psychiatry 1992; 37: 234-9.

26 Thompson MP, Kingree JB, Desai S. Gender differences in long-term health consequences of physical abuse of children: data from a nationally representative survey. Am J Public Health 2004; 94: 599-604.

27 Teicher MH, Andersen SL, Polcari A, Navalta CP, Kim DM. The neurobiological consequences of early stress and childhood maltreatment. NeurosCi Biobehav Rev 2003; 27: 33-44.

28 Renaud J, Brent DA, Birmaher B, Chiappetta L, Bridge J. Suicide in adolescents with disruptive disorders. J Am Acad Child Adolesc Psychiatry 1999; 38: 846-51.

29 Turecki G. Dissecting the suicide phenotype: the role of impulsive-aggressive behaviours. J Psychiatry Neurosci 2005; 30: 398-408.

30 Hébert $\mathrm{H}$, Tremblay C, Parent N, Daignault IV, Piché C. Correlates of behavioral outcomes in sexually abused children. J Fam Violence 2006; 21 287-99.

31 Brown J, Cohen $\mathrm{P}$, Johnson JG, Smailes EM. Childhood abuse and neglect: specificity of effects on adolescent and young adult depression and suicidality. J Am Acad Child Adolesc Psychiatry 1999; 38: 1490-6.

32 Allen DM, Farmer RG. Family relationships of adults with borderline personality disorder. Compr Psychiatry 1996; 37: 43-51. 